\title{
PENGUKURAN RESPONS SPEKTRA KOTA PADANG MENGGUNAKAN METODA PROBABILITAS
}

\author{
Delfebriyadi $^{1}$, Rudy Ferial ${ }^{2}$, Agasi Yudha Bestolova ${ }^{3}$
}

\begin{abstract}
ABSTRAK
Makalah ini memaparkan hasil studi hazard kegempaan dengan suatu teknik analisis probabilistik terhadap wilayah kota Padang yang dilakukan berdasarkan kriteria desain yang disyaratkan dalam SNI 03-1726-2002, yaitu umur bangunan 50 tahun dan nilai probabilitas terlampaui 10\%. Analisa hazard kegempaan dilakukan berdasarkan teori probabilitas total dan menggunakan pemodelan sumber gempa 2-D. Respons spektra desain di permukaan tanah diperkirakan berdasarkan faktor amplifikasi yang mengacu pada NEHRP 1997. Hasil akhir yang diperoleh adalah respons spektra percepatan desain permukaan tanah untuk kota Padang dengan periode ulang 500 tahun.
\end{abstract}

Kata Kunci: analisis hazard kegempaan, teori probabilitas, respon spektra

\section{PENDAHULUAN}

Letak geografis wilayah Indonesia yang berada pada pertemuan tiga lempeng tektonik utama yaitu lempeng Indo-Australia, lempeng Eurasia, dan lempeng Philipina, menjadikan Indonesia sebagai salah satu negara yang memiliki potensi aktivitas seismik cukup tinggi dan rawan terhadap bahaya gempa. Perkiraan besarnya beban atau percepatan gempa yang handal dalam perencanaan masih dapat dikaji secara lebih mendalam, mengingat sangat penting dan berpengaruhnya hal tersebut baik melingkupi aspek keamanan maupun efisiensi suatu desain bangunan, tanpa meninggalkan atau bahkan memungkinkan dapat melengkapi atau mengevaluasi peraturan-peraturan standar yang ada.

Pada makalah ini, dilakukan studi analisis hazard kegempaan untuk lokasi ditinjau, untuk menjembatani laju pembangunan yang pesat dan potensi aktivitas seismik yang cukup tinggi pada wilayah kota Padang.

\section{TINJAUAN SEISMOTEKTONIK}

Dalam kajiannya tentang resiko gempa, perlu diidentifikasikan secara geologi dan seismologi adanya beberapa zona sumber gempa aktif yang memiliki potensi dan kontribusi seismik signifikan terhadap wilayah kota Padang seperti zona subduksi Sumatera dan zona patahan Semangko. Zona patahan Semangko merupakan jalur patahan yang terbentuk akibat tabrakan lempeng Indo Australia yang bergerak dengan kecepatan relatif 50 hingga $60 \mathrm{~mm} /$ tahun terhadap lempeng Eurasia yang relatif diam. Keberadaan patahan ini juga berpotensi untuk menyebabkan sejumlah gempa bumi dangkal yang bersifat merusak.

\section{PARAMETER HAZARD KEGEMPAAN}

Parameter hazard kegempaan dapat menunjukkan aktifitas kegempaan pada suatu wilayah. Sebelum melakukan analisis hazard kegempaan, terlebih dahulu perlu dilakukan evaluasi terhadap seluruh data kejadian gempa yang pernah terjadi. Selanjutnya dilakukan pengolahan data gempa,

${ }^{1}$ Dosen Jurusan Teknik Sipil Universitas Andalas,delfebrix@yahoo.co.id

${ }^{2}$ Dosen Jurusan Teknik Sipil Universitas Andalas,

${ }^{3}$ Mahasiswa Jurusan Teknik Sipil Universitas Andalas, 
pembuatan model zona sumber gempa, perhitungan $b$-value dan annual rate, penentuan magnitude maksimum dan slip rate, serta pemilihan fungsi atenuasi.

\subsection{Pengumpulan dan Pengolahan Data Gempa}

Data-data kejadian gempa historis diperoleh dari data preliminary National Earthquake Information Centre-USGS (NEIC-USGS), International Seismological Centre (ISC) dan EHB (Engdahl, van der Hilst and Buland, 1998) untuk periode 1900-2007. Data-data yang berasal dari katalog gempa tersebut perlu dikoreksi dan diproses dengan menggunakan prinsip-prinsip statistik sebelum digunakan dalam analisis untuk mengurangi bias dan mendapatkan hasil yang optimal. Kejadian gempa dari gabungan katalog tersebut meliputi area mulai $90^{\circ} \mathrm{BT}$ hingga $112^{\circ} \mathrm{BT}$ dan $10^{\circ}$ LU hingga $8^{\circ} \mathrm{LS}$, dan data gempa lengkap dengan magnitude lebih besar atau sama dengan 5 dengan kedalaman maksimal 200 km, mulai tahun 1973 hingga 2007.

\subsection{Zona Sumber Gempa dan Pemodelannya}

Pada studi ini, zona sumber gempa terbagi atas zona gempa-gempa dangkal dan gempa-gempa dalam di sekitar subduksi Sumatera serta zona seismisitas rendah di daratan pulau Sumatera. Pemodelan zona sumber gempa ditentukan dengan menganalisa sudut penunjaman pertemuan lempeng yang ditujukan untuk memisahkan sumber gempa yang berbeda jenis mekanismenya yang terletak pada area yang sama. Pola penyebaran titik-titik hyposenter gempa disepanjang pola tektonik dapat diperkirakan dengan membagi zona sumber gempa tersebut menjadi beberapa segmen dan mengambil potongan melintang distribusi episenter sumber gempa pada setiap segmen tersebut (Gambar 1.).

Parameter $a$-b didapatkan dari pengelompokan data berdasarkan area sumber gempa dan jenis mekanismenya, dan ditentukan dengan menggunakan model Guttenberg-Richter recurrent relationship (Gutenberg, 1994) dan dengan model Maximum Entropy Principle (Delfebriyadi, 2011)

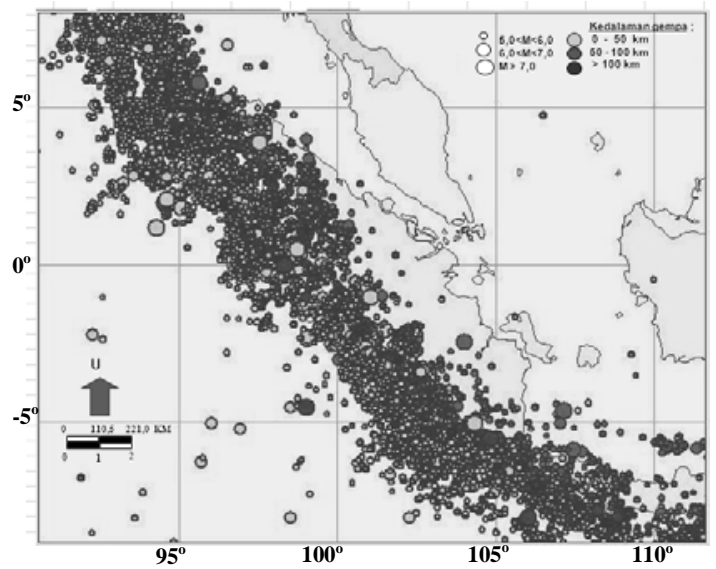

Gambar 1. Sebaran Sumber Gempa Periode 1900-2007 (Dong, 1984)

Pada zona gempa-gempa dangkal di sekitar subduksi Sumatera terhitung sejumlah 91 buah kejadian gempa utama dengan $M_{w}>5,0$ dalam rentang mulai dari tahun 1973. Kejadian gempa dengan magnitude terbesar $\left(M_{w} 9,0\right)$ terjadi wilayah perairan Aceh pada tanggal 26 Desember 2004 (National Earthquake Information Center, 2005) yang juga menimbulkan gelombang tsunami yang memporak-porandakan wilayah daratan di pesisir pantai wilayah Aceh dan sekitarnya. Nilai ratarata sebesar 0,64 didapatkan untuk memperkirakan $b$-value pada zona ini.

\section{J JRNAL REKAYASA SIPIL}


Untuk zona gempa-gempa dalam di sekitar subduksi Sumatera didapatkan sejumlah 130 buah kejadian gempa utama dengan $M_{w}>5,0$ dalam rentang mulai dari tahun 1973. Kejadian gempa dengan magnitude terbesar $\left(M_{w} 7,0\right)$ pada rentang tahun pengamatan itu juga terjadi wilayah Aceh pada bulan April 1983. Nilai rata-rata sebesar 1,03 didapatkan untuk memperkirakan $b$-value pada zona ini (Gambar 2.)

Zona patahan Sumatera tidak seproduktif zona subduksi Sumatera dalam menghasilkan gempagempa yang signifikan. Dalam zona ini diperoleh 58 buah kejadian gempa utama dengan $M_{w}>5,0$ dalam rentang mulai dari tahun 1973. Nilai magnitude terbesar pada rentang tahun pengamatan itu adalah $M_{w}$ 7,2 dan nilai $b$-value diperkirakan sebesar 0,75. Permodelan sumber gempa dapat dilihat pada Gambar 3.

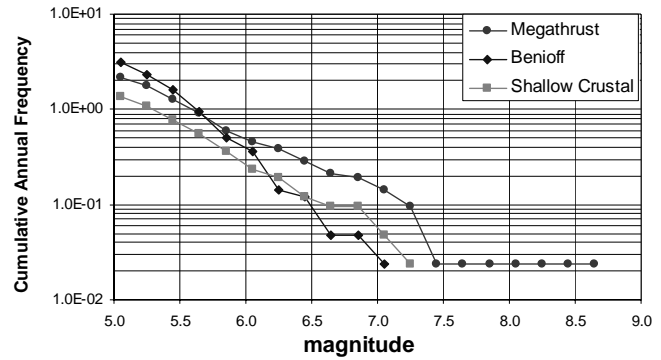

Gambar 2. Frekuensi Kejadian Gempa Kumulatif (Dong, 1984)

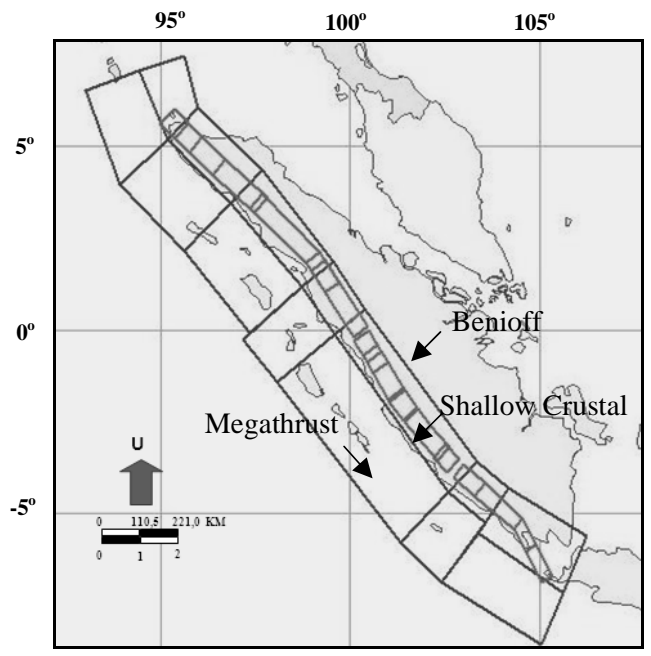

Gambar 3. Pemodelan Sumber Gempa (Dong, 1984)

\subsection{Fungsi Atenuasi}

Beberapa fungsi atenuasi telah dipublikasikan oleh sejumlah peneliti berdasarkan rekaman percepatan gempa yang pernah terjadi dan kondisi site lokasi kajiannya. Fungsi atenuasi yang dipakai pada studi ini adalah persamaan yang dikemukakan oleh Young et al. Untuk jenis sumber gempa pada area subduksi dan persamaan yang dikemukakan oleh Boore et al. Untuk jenis gempa strike slip pada area shallow crustal. 


\section{ANALISIS HAZARD KEGEMPAAN}

Analisis hazard kegempaan dimulai dengan mengembangkan model matematik yang akan digunakan untuk memperkirakan kemungkinan kejadian gempa dalam level skala magnitude atau intensitas tertentu pada interval periode ulang untuk suatu daerah tertentu. Analisis ini menghasilkan parameter desain seismik seperti percepatan maksimum dan kecepatan maksimum yang dapat terlampaui untuk probabilitas serta periode ulang tertentu. Pada makalah ini, percepatan gempa di batuan dasar diperoleh dari hasil analisis berdasarkan teori probabilitas total yang dikembangkan oleh McGuire 1976 berdasarkan konsep probabilitas yang diajukan Cornell 1968.

Probabilitas bahwa suatu ground motion $\boldsymbol{a}$ melebihi suatu nilai tertentu $\boldsymbol{a}^{*}$ dihitung untuk suatu potensi gempa pada suatu lokasi sumber gempa tertentu dan kemudian dikalikan dengan probabilitas bahwa suatu gempa dengan magnitude tertentu akan terjadi pada lokasi tersebut. Dengan mengasumsikan bahwa magnitude $\mathrm{M}$ dan jarak $\mathrm{R}$ adalah variabel acak independen yang kontinus, maka probabilitas terlampaui dapat dituliskan dalam bentuk integrasi persamaan berikut :

$$
P_{\left(a \geq a^{*}\right)}=\int_{M} \int_{R} P_{\left(a \geq a^{*} ; m, r\right)} f_{M(m)} f_{R(r)} d r d m
$$

dimana :

$\mathrm{f}_{\mathrm{M}}=$ fungsi distribusi dari magnitude.

$\mathrm{f}_{\mathrm{R}}=$ fungsi distribusi dari jarak.

$P\left(a \geq a^{*} ; m, r\right)=$ probabilitas berkondisi dari intensitas $\boldsymbol{a}$ yang sama atau lebih besar dari intensitas $\boldsymbol{a}^{*}$ di suatu lokasi dengan kekuatan gempa $\mathrm{M}$ dan jarak sumber $\mathrm{R}$ yang diperoleh dari fungsi ateunasi.

Jika site yang ditinjau berada dalam suatu daerah dengan beberapa sumber gempa (Ns) dimana setiap sumber memiliki rate untuk threshold magnitude sebesar

$$
v=\exp \left[\alpha-\beta \cdot m_{o}\right]
$$

maka total kejadian gempa terlampaui untuk daerah tersebut adalah ;

$$
\lambda\left(a \geq a^{*}\right)=\sum_{i=1}^{N s} v_{i} \cdot P\left(a \geq a^{*}\right)
$$

Periode ulang dari parameter gerakan tanah terlampaui adalah sebanding dengan perbandingan terbalik dari kejadian gempa tahunan. Logic tree (Gambar 4.) digunakan untuk menentukan pembobotan pada masing-masing parameter yang dipergunakan dan untuk untuk mengatasi nilai ketidak-pastian pada analisis hazard kegempaan dengan menggunakan metode probabilitas.

Gambar 6 - 8. memperlihatkan hasil perhitungan hazard kegempaan berupa total jumlah kejadian gempa bumi tahunan terlampaui rata-rata untuk semua sumber gempa. Gambar 9. memperlihatkan hasil perhitungan hazard kegempaan berupa spektral percepatan (SA) di batuan dasar pada lokasi kajian untuk suatu periode ulang pada beberapa perioda spektral. Untuk periode ulang 500 tahun di wilayah Padang didapatkan peak ground acceleration (PGA) di batuan dasar sebesar 0,30g, SA untuk $\mathrm{T}=$ 0,2 detik sebesar 0,69g, dan SA untuk $\mathrm{T}=1,0$ detik sebesar 0,26g (Gambar 5.).

\section{I JURNAL REKAYASA SIPIL}




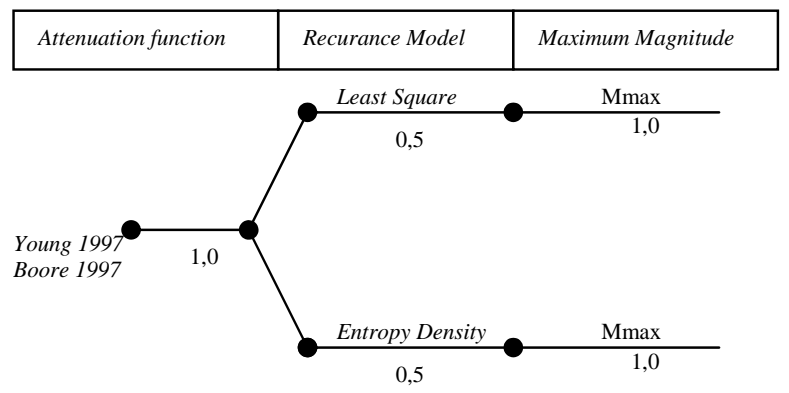

Gambar 4. Formulasi Logic Tree Untuk Sumber Gempa Subduksi dan Shallow Crustal (Dong, 1984)

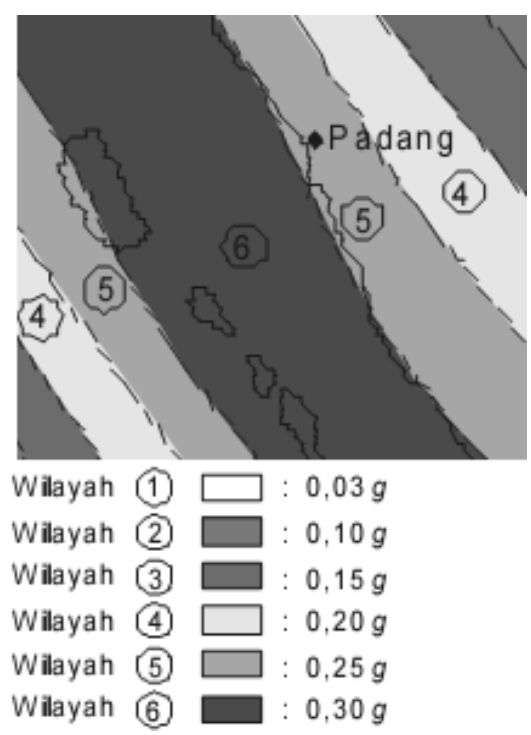

Gambar 5. Peta Percepatan Maksimum di Batuan Dasar

Pada Periode Ulang 500 Tahun di Wilayah Kota Padang (Standar Nasional Indonesia, 2000)

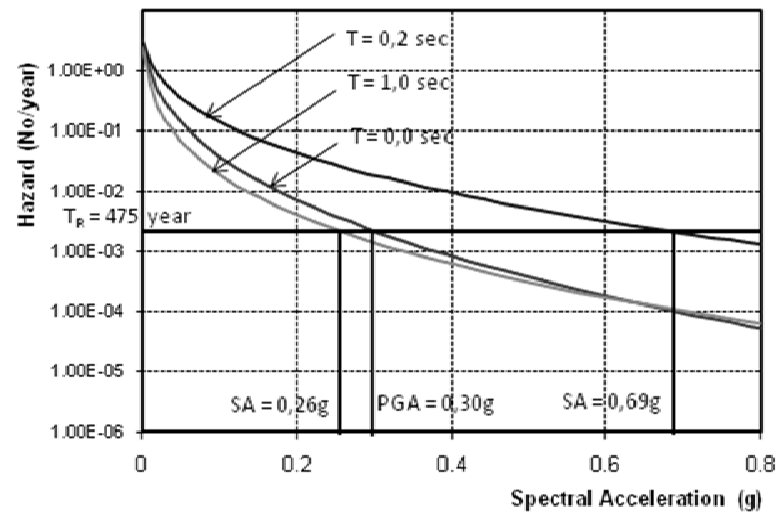

Gambar 6. Total Jumlah Kejadian Tahunan Terlampaui

Rata-Rata Untuk Periode Spektral 0.0s, 0.2s

dan 1.0s Pada Redaman 5\% 


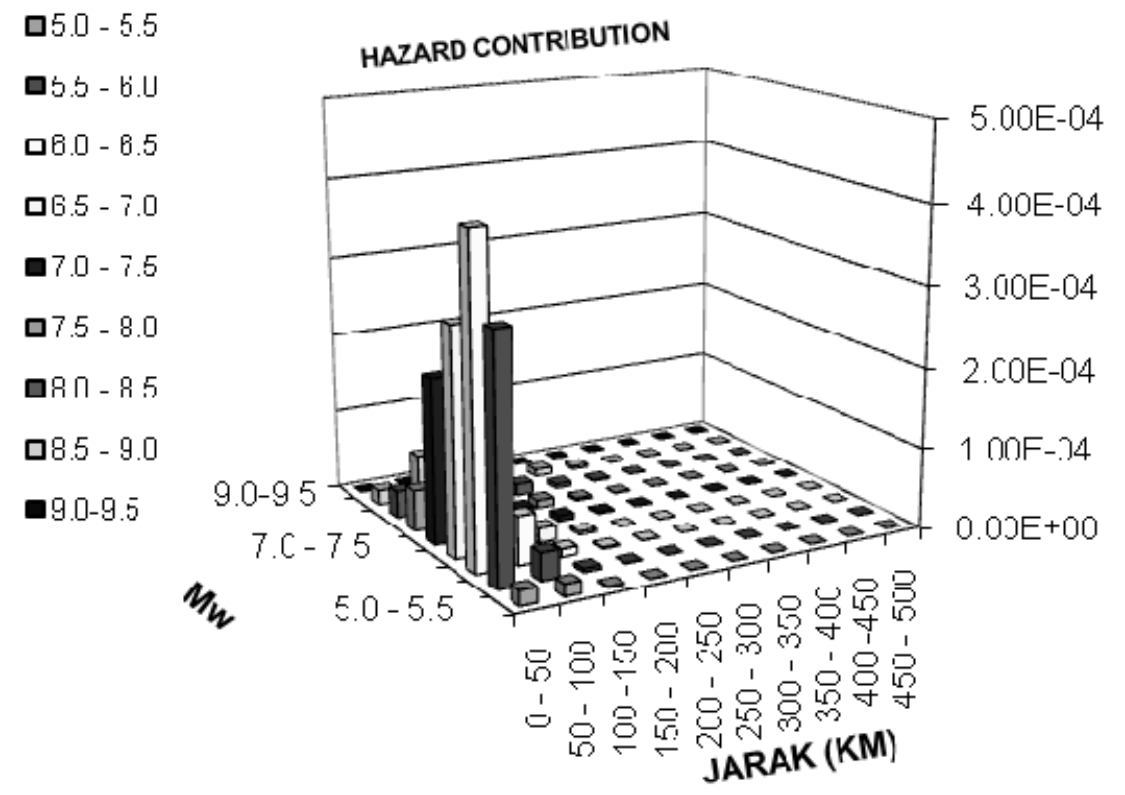

Gambar 7. Kontribusi Kejadian Tahunan di Kota Padang yang Disumbangkan Sumber Gempa Subduksi dan Shallowcrustal untuk Perioda 0,2 Detik , Spektral Percepatan 0,69g

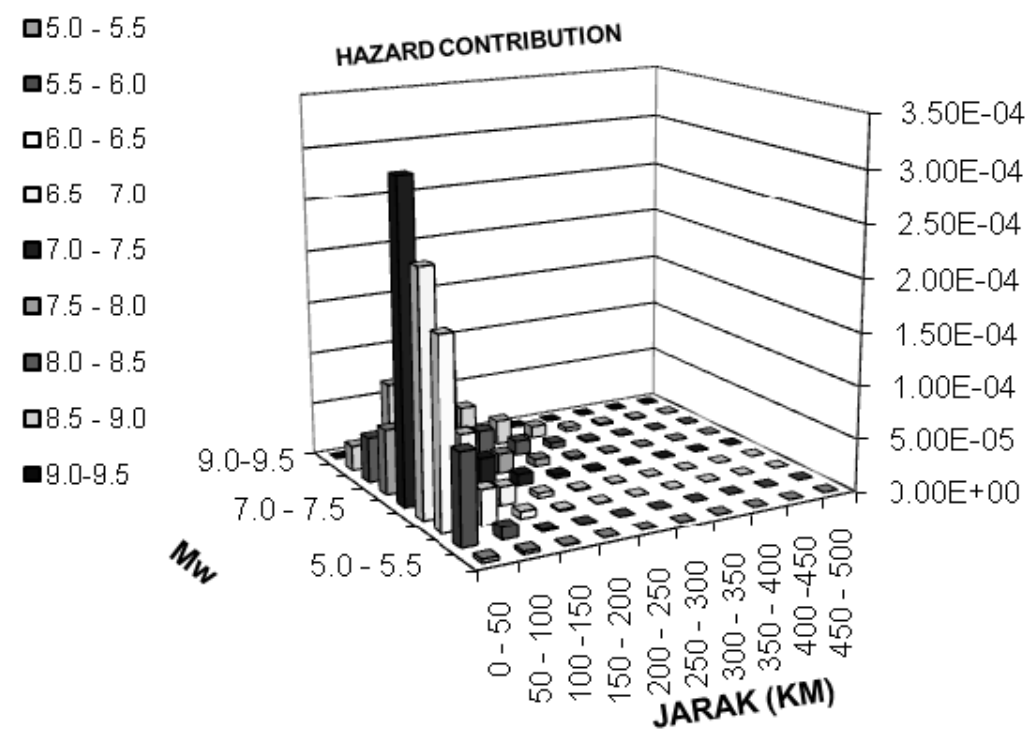

Gambar 8. Kontribusi Kejadian Tahunan di Kota Padang yang Disumbangkan Sumber Gempa Subduksi dan Shallow Crustal untuk Perioda 1,0 Detik , Spektral Percepatan 0,26g 


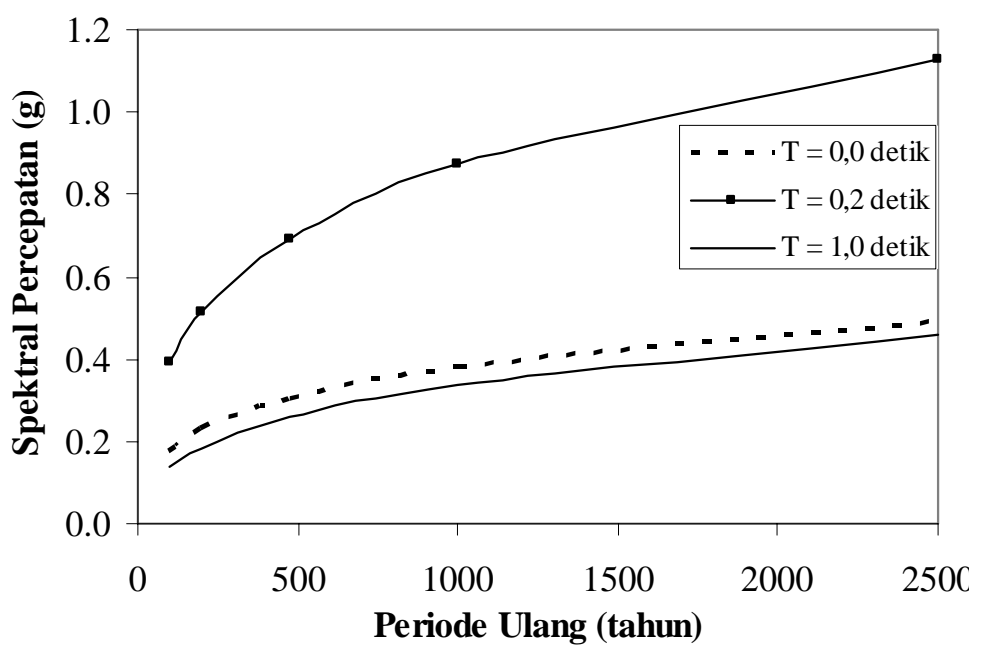

\section{Gambar 9. Spektral Percepatan di Batuan Dasar Pada Lokasi Kajian Untuk Periode Ulang Tertentu}

\section{RESPONS SPEKTRA DI PERMUKAAN TANAH}

Kondisi tanah lokal diklasifikasikan berdasarkan nilai rata-rata parameter kecepatan gelombang geser (Vs), nilai hasil Tes Penetrasi Standar ( $\left.\mathrm{N}_{\text {-spT }}\right)$ ataupun kuat geser niralir (Su) pada tanah hingga kedalaman $30 \mathrm{~m}$ dari permukaan tanah dan dianalisis menurut 3 kelas tanah, yaitu; tanah keras (very dense soil and soft rock), tanah sedang (stiff soil profile) dan tanah lunak (soft soil profile).

Respons spektra desain di permukaan tanah diperkirakan berdasarkan faktor amplifikasi yang mengacu pada NEHRP (1997).

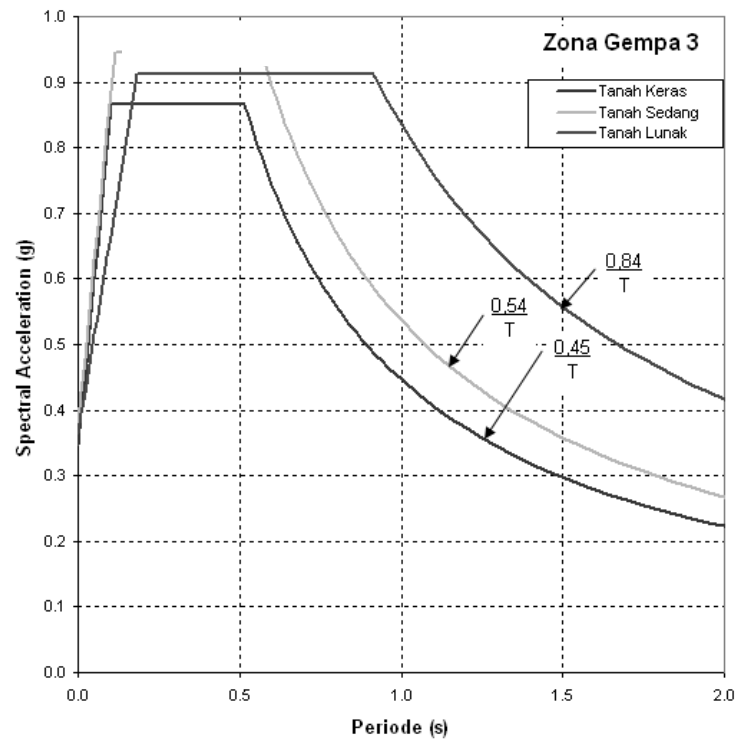

Gambar 10. Respons Spektra Percepatan Desain Kota Padang Untuk Periode Ulang 500 Tahun 


\section{KESIMPULAN}

Dari hasil analisa hazard kegempaan yang telah dikerjakan, terdapat kenaikan tingkat seismisitas pada wilayah kota Padang jika dibandingkan dengan tingkat seismisitas pada peta gempa SNI 031726-2002. Percepatan tanah puncak di lapisan batuan dasar dengan periode ulang 500 tahun yang disyaratkan oleh SNI 03-1726-2002 untuk wilayah Padang adalah sebesar 0.25g (Gambar 5), sedangkan hasil perhitungan dengan perioda ulang yang sama menunjukkan nilai 0.30g (Gambar 10).

\section{DAFTAR KEPUSTAKAAN}

Boore, D.M., Joyner, W.B., Fumal, T.E., (1997), “Equations for estimating horizontal response spectra and peak acceleration from Western North American earthquakes : a summary of recent work", Seismological Research Letters 68, 128-153.

Cornell, C. A.,(1968), “Engineering seismic risk analysis”, Bulletin of theSeismological Society of America 58, 1583-1606.

Delfebriyadi, (2011), "Seismic Hazard Assessment of Padang City Using Probabilistic Method", Asian Transaction on Engineering, Vol. 01(5), 56-62.

Dong, W. M., Bao, A. B., Shah, H. C., (1984), "Use of Maximum Entropy Principle in Earthquake Recurrence Relationship”, Bulletin of the Seimological Society of America, Vol. 74, No. 2, pp. 725-737.

Delfebriyadi, (2011), "Seismic Hazard Assessment of Padang City Using Probabilistic Method", Asian Transactions on Engineering, Vol. 01, Issue05.

Delfebriyadi, (2010), "Respons Spektrum Wilayah Kota Padang Untuk Perencanaan Bangunan Gedung Tahan Gempa”, Jurnal TEKNIKA, Universitas Andalas, Vol.1(33), 20-24.

Federal Emergency Management Agency, (1997), "NEHRP Recommended Provisions for Seismic Regulation for New Buildings and Other Structures", Part 1, Provisions, FEMA 302, Prepared by Building Seismic Safety Council, Washington, DC, 337 p.

Gutenberg, B., Richter, C.F., (1944), "Frequency of Earthquakes in California”, Bulletin of the Seismological Society of America, Vol. 34, No. 4, pp. 185-188.

McGuire, R., (1976), "Fortran Computer Program for Seismic Risk Analysis”, Open-File Report 76-67, U.S. Geological Survey.

National Earthquake Information Center, (2005), “Magnitude 9.0 off the West Coast of Northern Sumatra - Sunday December 26, 2004 at 00:58:53 Coordinated Unersal Time, United States Geological Survey, February $15^{\text {th }}, 2005$

Available_http://earthquake.usgs.gov.eqinthenews/2004/usslav/

Standar Nasional Indonesia, (2002), “Tata Cara Perencanaan Ketahanan Gempa untuk Bangunan Gedung (SNI 03-1726-2002”), Badan Standardisasi Nasional. 